\title{
Strategies for Sustainable Food Processing and Preservation
}

\author{
C.A. Olurankinse \\ Department Of Home Economics, Adeyemi College Of Education, Ondo, Nigeria
}

\begin{abstract}
The time to ensure abundance in food supply to feed the citizenry cannot be better than the present time when the population of Nigeria is increasing at alarming rate. Developing food processing and preservation technologies that can curb food losses and wastage during glut seasons cannot be overemphasized. This paper dealt with various food processing techniques as well as preservation methods and compared them with what obtains in the western world to bring out possible cross fertilization of useful ideas for the Nigerian society.
\end{abstract}

Key words: cloning, curing, nutrition, Anaerobiosis, food technology, biotechnology

\section{Introduction}

Foods in Nigeria are seasonal, but they are produced in great quantities (i.e. in abundance) during their harvest seasons. The weather conditions which are very favourable to microbial food spoilage constitutes a menace in food management. The human food is attacked by many organisms that thereby compete with man for his food. Also, illiteracy, poor farming techniques and poor social amenities like electricity failure and bad roads aid spoilage.

In addition, it is observed that climate change has compounded the issue of food processing and preservation. Some foods are available when least expected, thus leading to wastage. Some get ripen when not fully matured. Also, many home makers lack good nutrition knowledge on food processing and preservation. These have prompted the idea of food preservation in all users of food in order to consume wholesome foods. Food preservation deals with the ability of increasing the shelf life of food i.e. increase the keeping quality of foods for future use by man.

Whitney et. al. (1991) likened the human body to an ingenious, beautifully constructed and economically run engine. Like all good engines, it requires high quality constructive materials, efficient repair and adequate fuel supply if it is to do its work satisfactorily. The human body needs quality and adequate food to keep the body functioning properly. These needs are supplied by the foods we eat. The objectives of this study were to: (i) identify the local food preservation techniques practiced in Nigeria (ii) evaluate sustainable food processing and preservation techniques.

\section{Food Preservation}

The term food preservation refers to any one of a number of techniques used to prevent food from spoiling (Okeke, 2009). It includes methods such as canning, pickling, drying and freeze-drying, irradiation, pasteurization, smoking, and the addition of chemical additives. Food preservation has become an increasingly important component of the food industry as fewer people eat foods produced on their own lands, and as consumers expect to be able to purchase and consume foods that are "out of season." The old methods of food preservation in Nigeria include the following;

\section{Smoking}

Early humans probably discovered by accident that certain foods exposed to smoke seem to last longer than those that are not. Meat, fish, fowl, and cheese were among such foods. Olusanya et.al.(2005) claims that the compounds present in wood smoke have anti-microbial actions that prevent the growth of organisms that cause spoilage.

Today, the process of smoking has become a sophisticated method of food preservation with, both hot and cold forms in use. Hot smoking is used primarily with fresh or frozen foods, while cold smoking is used most often with salted products. The most advantageous conditions for each kind of smoking-air velocity, relative humidity, length of exposure, and salt content, for example are now generally understood and applied during the smoking process. For example, electrostatic precipitators can be employed to attract smoke particles and improve the penetration of the particles into meat or fish (Bentley, 1998). So many alternative forms of preservation are now available that smoking no longer holds the position of importance it once did with ancient peoples. More frequently the process is used to add interesting and distinctive flavors to foods. 
Since most disease causing organisms require a moist environment to survive and multiply, drying is a natural technique for preventing spoilage. Indeed, the act of simply leaving foods out in the sun and wind to dry out is probably one of the earliest forms of food preservation. Evidence for the drying of meats, fish, fruits, and vegetables go back to the earliest recorded human history.

At some point, humans also learned that the drying process could be hastened and improved by various mechanical techniques. Bentley (1998) added that the Arabs learned early that apricots could be preserved almost indefinitely by macerating them, boiling them, and then leaving them to dry on broad sheets. The product of this technique, quamaradeen, is still made by tile, same process in modern Muslim countries. He further claimed that a host of dehydrating techniques are known and used. The specific technique adopted depends on the properties of the food being preserved. For example, a traditional method for preserving rice is to allow it to dry naturally in the fields or on drying racks in barns for about two weeks. After this period of time, the native rice is threshed and then dried again by allowing it to sit on straw mats in the sun for about three days.

Modern drying techniques make use of fans and heaters in controlled environments. Such methods avoid the uncertainties that arise from leaving crops in the field to dry under natural conditions. Controlled temperature air drying is especially popular for the preservation of grains such as maize, barley, and bulgur (Bentley 1998). Similarly, he states that vacuum drying is a form of preservation in which a food is placed in a large container from which air is removed. Water vapor pressure within the food is greater than that outside of it, and water evaporates more quickly from the food than in a normal atmosphere. Vacuum drying is biologically desirable since some enzymes that cause oxidation of foods become active during normal air drying. These enzymes do not appear to be as active under vacuum drying conditions. However, two of the special advantages of vacuum drying is that the process is more efficient at removing water from a food product, and it takes place more quickly than air drying. In one study, for example, the drying time of a fish fillet was reduced from about 16 hours by air drying to six hours as a result of vacuum drying.

\section{Salting/Lye}

It is known that salt binds with water molecules and thus acts as a dehydrating agent in foods. A high level of salinity may also impair the conditions under which pathogens can survive. In any case, the value of adding salt to foods for preservation has been well known for centuries.

Sugar appears to have effects similar to those of salt in preventing spoilage of food. The use of either compound (and of certain other natural materials) is known as curing. A desirable side effect of using salt or sugar as a food preservative is, of course, the pleasant flavor each compound adds to the final product.

Curing can be accomplished in a variety of ways. Meats can be submerged in a salt solution known as brine, salt rubbed on the meat by hand. The injection of salt solutions into meats has also become popular. Food scientists have now learned that a number of factors relating to the food product and to the preservative conditions affect the efficiency of curing. Some of the food factors include the type of food being preserved, the fat content, and the size of treated pieces. Preservative factors include brine, temperature, concentration and the presence of impurities (Riddervold, 1988 and Okeke,2009).

\section{Freezing}

Freezing is an effective form of food preservation because the pathogens that cause food spoilage are killed or do not grow very rapidly at reduced temperatures. The process is less effective in food preservation than are thermal techniques such as boiling because pathogens are more likely to be able to survive cold temperatures than hot temperatures. In fact, one of the problems surrounding the use of freezing as a method of food preservation is the danger that pathogens deactivated (but not killed) by the process will once again become active when the frozen food thaws.

A number of factors are involved in the selection of the best approach to the freezing of foods, including the temperature to be used, the rate at which freezing is to take place, and the actual method used to freeze the food. Foods actually begin to freeze at different temperatures because of differences in cellular composition, ranging from about $31^{\circ} \mathrm{F}\left(-0.6^{\circ} \mathrm{C}\right)$ for some kinds of fish to $19^{\circ} \mathrm{F}\left(-7^{\circ} \mathrm{C}\right)$ for some kinds of fruits (Thelma, et al 1981 and Riddervold, 1988).

\section{Fermentation}

Fermentation is $a$ naturally occurring chemical reaction by which a natural food is converted into another form by pathogens. It is a process in which food "goes bad," but results in the formation of an edible product. Perhaps the best example of such a food is cheese. Fresh milk does not remain in edible condition for a very long period of time. Its $\mathrm{pH}$ is such that harmful pathogens begin to grow in it very rapidly. Early humans discovered, however, that the spoilage of milk can be controlled in such a way as to produce a new product like cheese, etc; (Olusanya et.al.2005).

Burial in the ground 
Shephard (2006) stated that burial of food can preserve it due to a variety of factors like lack of light, lack of oxygen, cool temperatures, $\mathrm{pH}$ level, or desiccants in the soil. Burial may be combined with other methods such as salting or fermentation. Many root vegetables are very resistant to spoilage and require no other preservation other than storage in cool dark conditions, for example by burial in the ground, such as in a storage clamp.

\section{Controlled use of micro-organism}

Some foods, such as many cheeses, wines, and beers will keep for a long time because their production uses specific micro-organisms that combat spoilage from other less benign organisms. These micro-organisms keep pathogens in check by creating an environment toxic for themselves and other micro-organisms by producing acid or alcohol. Starter micro-organisms, salt, hops, controlled (usually cool) temperatures, controlled (usually low) levels of oxygen and/or other methods are used to create the specific controlled conditions that will support the desirable organisms that produce food fit for human consumption (Whitney, et al 1991 and Shephard, 2006).

\section{High pressure food preservation}

High pressure food preservation refers to high pressure used for food preservation. "Pressed inside a vessel exerting 70,000 pounds per square inch or more, food can be processed so that it retains its fresh appearance, flavour, texture and nutrients while disabling harmful microorganisms and slowing spoilage." Alltrista Consumer Product (2006) stated that adequate commercial equipment was developed by 2001 and that by 2005 the process used for products ranging from orange juice to guacamole to deli meats was widely sold. The modern methods of food preservation are substantiated below which could be adopted or integrated with the local methods to enhance food availability of food throughout the year include the following

\section{Canning}

Shephard (2006) described the process of canning thus: the food is peeled, cured, and diseased portions are removed. For canning, containers are evacuated and placed in a pressurised steam sterilizer, similar to an autoclave at $121^{\circ} \mathrm{C}$. This removes especially Bacillus and Clostridium spores. If canning is defective, foods may become contaminated by anaerobic bacteria which produce gas. These are species of Clostridium and coliform bacteria (a group of Gram-negative nonspore-forming rods which ferment lactose to acid and gas at $32^{\circ} \mathrm{C}$ in 48 hours).

\section{Low temperature}

Exposure of microorganisms to low temperatures reduces their rates of growth and reproduction. This principle is used in refrigeration and freezing. Microbes are not killed. In refrigerators at $5^{\circ} \mathrm{C}$, foods remain unspoiled. In a freezer at $-5^{\circ} \mathrm{C}$ the crystals formed tear and shred microorganisms. It may kill many of the microbes. However, some are able to survive. Salmonella spp. and streptococci survive freezing. For these types rapid thawing and cooking is necessary. Deep freezing at $-60^{\circ} \mathrm{C}$ forms smaller crystals. It reduces biochemical activities of microbes.

\section{Blanching}

Blanching of fruits and vegetables, by scalding with hot water or steam prior to deep freezing, inactivate plant enzymes that may produce toughness, change in colour, etc. A brief scalding prior to freezing also reduces the number of microorganisms on the food surface by up to 99 percent and enhances the colour of green vegetables (Shephard 2006).

\section{Spray Drying}

Bentley (1998) discussed that a spray dryer expels a fine mist of liquid such as coffee into a barrel cylinder containing hot air. There may be a heated drum onto which liquids like soup may be poured. Another machine is a belt heater that exposes liquids as milk to a steam of hot air that evaporates water and produces dried milk solids. A common process of freeze drying or lyophilization is used these days. The food is deep frozen, after which the water is drawn off by a vacuum pump in a machine. The dry product is then sealed in foil and is reconstituted with water. This method is very useful for storing, transporting and preserving bacterial cultures.

\section{Osmotic pressure}

The principle of osmosis is applied. Foods are preserved by adding salts and sugars to them. These chemicals remove the water out of microbial cells causing them to shrink thus stopping their metabolism. Jams, jellies, 
fruit syrups, honey etc. are preserved by high sugar concentration. Fish, meat beef and vegetable products are preserved with salt (Alltrista Consumer Product ,2006).

\section{Chemical preservatives}

The most commonly used are the acids, such as sorbic acid, benzoic acid and propionic acid. These check mainly the growth of yeasts and moulds. Sorbic acid is used for preservation of syrups, salads, jellies and some cakes. Benzoic acid is used for beverages, margarine, apple, cider, etc, Propionic acid is an ingredient of bread and bakery products. Sulphur dioxide, as gas or liquid is also used for dried fruits, molasses and juice concentrates. Ethylene oxide is used for spices, nuts and dried fruits (Bentley, 1998 and Shephard, 2006).

\section{Radiation}

Ultra Violent rays are used in meat storage facilities to reduce surface contamination, on meat products. Gamma rays are also used for some meat products.

\section{Anaerobiosis}

Packaging of food products under anaerobic conditions - anaerobiosis is effective in preventing aerobic spoilage process. Vacuum packing in an airtight container is used to eliminate air (Frazier, 1967 and Shephard, 2006).

\section{Controlled atmospheres}

Such atmospheres containing $10 \% \mathrm{CO}_{2}$ are used to preserve stored food products as apples and pears. This checks fungal growth. Ozone can also be added, (Alltrista Consumer Product, 2006).

\section{Other methods}

These are asepsis i.e. washing utensils that come in contact with food, filtration and centrifugation to remove microbes. Filtration is used for fruit juices, other drinks, etc. Bacteriological filters are used in industries. (Bentley, 1998)

\section{Jellying}

Food may be preserved by cooking a material that solidifies to form a gel. Such materials include gelatine, agar, maize flour and arrowroot flour. Some foods naturally form a protein gel when cooked such as eels and elvers, and sipunculid worms which are a delicacy in the town of Xiamen in Fujian province of the People's Republic of China. Jellied eels are a delicacy in the East End of London where they are eaten with mashed potatoes. Potted meats in aspic, (a gel made from gelatine and clarified meat broth) were a common way of serving meat off-cuts in the UK until the 1950s. Many jugged meats are also jellied. Fruit preserved by jellying is known as jelly, marmalade, or fruit preserves. In this case, the jellying agent is usually pectin, either added during cooking or arising naturally from the fruit. Most preserved fruit is also sugared in jars. Heating, packaging, acid and sugar provide the preservation. (Shephard, 2006)

\section{Potting}

A traditional British way of preserving meat (particularly shrimp) is by setting it in a pot and sealing it with a layer of fat. Also common in potted chicken liver; (Shephard, 2006)

\section{Jugging}

Meat can be preserved by jugging which is the process of stewing the meat (commonly game or fish) in a covered earthenware jug or casserole. The animal to be jugged is usually cut into pieces, placed into a tightly sealed jug with brine or gravy, and stewed. Red wine and/or the animal's own blood is sometimes added to the cooking liquid. Jugging was a popular method of preserving meat until the middle of the 20th century. (Shephard, 2006)

\section{Pulsed Electric Field}

Pulsed Electric Field (PEF) processing is a method for processing cells by means of brief pulses of a strong electric field. PEF holds potential as a type of low temperature alternative pasteurization process for sterilizing food products. In PEF processing, a substance is placed between two electrodes, then the pulsed electric field is applied. The electric field enlarges the pores of the cell membranes which kills the cells and releases their contents. PEF for food processing is a developing technology still being researched. There have been limited industrial applications of PEF processing for the pasteurization of fruit juices. (Bentley, 1998) 


\section{Modified atmosphere}

Modified atmosphere is a way to preserve food by operating on the atmosphere around it. Salad crops which are notoriously difficult to preserve are now being packaged in sealed bags with an atmosphere modified to reduce the oxygen $\left(\mathrm{O}_{2}\right)$ concentration and increase the carbon dioxide $\left(\mathrm{CO}_{2}\right)$ concentration. There is concern that although salad vegetables retain their appearance and texture in such conditions, this method of preservation may not retain nutrients, especially vitamins. Grains may be preserved using carbon dioxide. A block of dry ice is placed in the bottom and the can is filled with grain. The can is then "burped" of excess gas. The carbon dioxide from the sublimation of the dry ice prevents insects, mold, and oxidation from damaging the grain. Grain stored in this way can remain edible for five years. Nitrogen gas $\left(\mathrm{N}_{2}\right)$ at concentrations of $98 \%$ or higher is also used effectively to kill insects in grain through hypoxia. However, carbon dioxide has an advantage in this respect as it kills the organisms. (Riddervold, 1988 and Shephard, 2006).

\section{Housekeeper's Nutrition knowledge on Food Preservation}

Nutrition knowledge on food preservation would foster food security and prevent hunger. Up till this time, illiteracy is still racing its ugly head to the extent that some housewives cannot identify the causes of food spoilage in some semi urban and rural areas in Nigeria. This is shown in the table below as revealed by a study carried out by Olurankinse (1995).

Table 1: Percentage distribution of respondents by knowledge of food spoilage

\begin{tabular}{|l|c|c|c|c|}
\hline $\begin{array}{l}\text { Observation of the colour, taste and odour of } \\
\text { foods }\end{array}$ & \multicolumn{2}{l|}{ High income housewives } & \multicolumn{2}{l|}{ income housewives } \\
\hline & Frequency & $\%$ & Frequency & $\%$ \\
\hline Spoilt foods manifest change in colour, odour and taste & 50 & 100 & 50 & 100 \\
\hline $\begin{array}{l}\text { Spoilt foods do not manifest any change in colour, odour } \\
\text { and taste }\end{array}$ & 00 & 00 & 00 & 00 \\
\hline Total & $\mathbf{5 0}$ & $\mathbf{1 0 0}$ & $\mathbf{5 0}$ & $\mathbf{1 0 0}$ \\
\hline Causes of food spoilage & & & & 01 \\
\hline Germs present in the food & 15 & 30 & 30 & 60 \\
\hline Water content of the food & 41 & 82 & 40 & 80 \\
\hline Electricity failure & 45 & 90 & 04 & 08 \\
\hline I don't really know & 00 & 00 & 04 & 16 \\
\hline The container in which the food is put & 00 & 00 & 08 & \\
\hline
\end{tabular}

Source: Olurankinse, C.A. (1995)

Note: Each of the respondents gave more than one cause of food spoilage.

Table 1 reveals that all the respondents, irrespective of their socio-economic statuses were aware of the fact that spoilt foods change in colour, taste and odour (i.e. the organoleptic properties change negatively). $82 \%$ of the high income housewives and60\% of the low income housewives respectively attributed the cause of food spoilage to the water content of the food. A low percentage (i.e. 8\%) of the low income housewives were ignorant of the causes of food spoilage may be due to their conservative attitudes.

\section{New Research in the Western World to Boost Food Production, Processing and Preservation}

Biotechnology is the use of living organisms to make a product or run a process to allow the identification and transfer of specific genes for specific traits. (IFIC, Nov/Dec; 2008).

IFIC (March/April, 2006) revealed that biotechnology is a food production method that uses no-till farming method to reduce carbon emissions, soil erosion, farming impart on the environment, crop loss and pesticides. It includes growing more foods on less land to protect natural resources and conserve fresh water through plants that use water more efficiently thus reducing global warming. Crops are preserved and made resistant to pests to combat global food crisis and higher food prices. In 2005, U.S. alone prevented the loss of approximately eight billion pounds of crop through the use of biotechnology. It also reduced fossil fuel use by 962 million $\mathrm{kg}$ of $\mathrm{CO}_{2}$ equivalent to the $\mathrm{CO} 2$ products of 427,556 average-sized family cars, as claimed by IFIC (Nov/Dec; 2008). Some African countries have embraced biotechnology. These countries are Zambia, South Africa and Kenya. Seven academics of science confirmed and guaranteed its safety. It is practiced in U.K; U.S; Brazil, India, Mexico, China. Its safety is farther guaranteed by American Medical Association and Society of Toxicology. (IFIC March/April, 2006).

Cloning is a form of animal biotechnology that retains desirable traits by producing animals that are identical twins. The products of such animals are processed and preserved for consumption to cater for feeding the expanding global population and foster food security. The percentage of Americans that accepted the 
consumption of preserved cloned animal products has risen from 36 percent in 2005 to 48 percent in 2008 . (IFIC, Nov./Dec; 2008).

Nanotechnology is the art and science of moving matter at the atomic or molecular scale to develop new products and processes. (IFIC Nov/Dec 2005). Weiss (2005) envisioned Nano foods as foods packaged in "smart packaging in which nanosensors are embedded to alert a consumer by means of a package color change due to contamination or the presence of pathogens such as E.coli, salmonella or listeria. Active packaging absorbs oxygen and keeps foods fresher for longer period. Also the use of "nanocapsules to deliver nutrients and antioxidants to targeted areas of the body at designated times is anticipated".

All the afore-mentioned technologies can be studied, followed and produced by Nigerian food technologists and food engineers to construct and fabricate food machines in line with our own local foods to combat any harvoc done by climate change and global warming.

\section{Conclusion}

This paper discusses recent or current food production and processes common in Nigeria and those from the western world that need to be incorporated in preservative industries in Nigeria. . It is therefore concluded that homemakers and food technologists as well as food engineers should be dynamic and move with time as condition warrants. They should make use of the food preservation methods with functional modifications. They should also make use of current or modern methods and embrace food technologies to boost food security and fight hunger.

\section{Recommendations}

Nigerian government, agriculturist and food scientist should work on biotechnology, cloning and nanotechnology to boost Nigerian food production and preservation.

- $\quad$ Farmers should take advantage of new and safe food technologies like cloning, biotech and nanotech.

- Government should increase awareness and uniform message to enhance sustainable agricultural food products.

- Government to plan and supply steady electricity to enhance the efforts of the citizens so as not to be futile.

- $\quad$ Housekeepers should update their nutrition knowledge and grab the use of contemporary or current research findings.

$$
-
$$

\section{References}

[1]. Alltrista Consumer Products, (2006) Ball Blue Book of Preserving. Muncie, IN: Jarden Home Brands.

[2]. Bentley, A. (1998). Eating for Victory: Food Rationing and the Politics of Domesticity. Urbana: University of Illinois Press.

[3]. Frazier, W.C. (1967) Food Microbiology. New Delhi: Tetra Magrow Publ. Co. Ltd.

[4]. IFIC Foundation (Nov/Dec; 2005) Food Insight. Nanotechnology: Does the Science of the small offer big possibilities for food and consumer products?

[5]. IFIC Foundation (March/April, 2006) Food Insight: Plant Biotechnology. Contributingto Food Security in Africa. Available at http://ific.org/foodinsight.

[6]. IFIC Foundation (Nov/Dec; 2008) Food Insight. Americans are more Aware of Sustainable Food Production. IFIC Releases New 2008 Food Biotechnology Survey.

[7]. Intergovernmental Panel on Climate Change (IPCC) (2007): The Physical Science Basis, Summary for Policy Makers; 2007. available at http://www.ecv.wa.gov/climatechange/whatis.htm

[8]. Okeke, S.U.N.(2009) Home Management for Schools and Colleges. Onitsha: Africana First

[9]. Publishers Plc.Olurankinse, C.A. (1995) Food Preservation Practices Among Housewives of Different Income Groups in Ilesa Town in Osun State. (An unpublished B.Ed. Home Economics Long Essay submitted to the Department of Home Economics, A.C.E., Ondo)

[10]. Olusanya, J.O., Oby, E. Anfani-Joe, M.E., Ogunyide, 1.0. and Egbuchulam, B. (2005) Foods and Nutrition for Senior Secondary Schools 1-3. Ibadan: University Press Ltd.

[11]. Riddervold, A. (1988) Food Conservation, London: Prospect.

[12]. Shephard, S. (2006) Pickled, Ported, and Canned: How the Art and Science of FoodPreserving Changed the World. New York: Simon and Schuster Paperbacks.

[13]. Thelma, J.P. and Rosa, K.P. (1981) Principles of Microbiology for Students of Food Technology. London: Hutchinson \& Co. (Publishers) Ltd.

[14]. Whitney, E.N., Cataldo, C.B. and Rolfes, S.R. (1991) Understanding Normal and Clinical Nutrition. New York: West Publishing Co. 